\title{
Posiciones docentes y construcciones en torno de lo común frente a la desigualdad en Argentina*
}

\author{
Alejandro Vassiliades ${ }^{\star \star}$
}

\section{RESUMEN}

Este artículo se propone dar cuenta de los sentidos en torno de lo común que tienen lugar en las posiciones docentes que maestras de tres escuelas primarias públicas de la provincia de Buenos Aires, Argentina, construyen frente a situaciones de desigualdad social y educativa, indagando acerca de los significados que atribuyen a su trabajo, y los problemas y desafíos que se formulan en torno de él. Estas escuelas trabajan con estudiantes que viven en condiciones de pobreza, en territorios surcados por diversas formas de desigualdad. La idea de lo común en la escolarización no tiene un contenido fijo e inmutable, sino que está compuesto de significaciones provisorias por las que se libran disputas, en las que intervienen -entre otros- el discurso pedagógico oficial y las diversas apropiaciones que los sujetos docentes realizan de él. En la construcción cotidiana de respuestas frente a situaciones que identifican como del orden de la desigualdad, los docentes desarrollan reflexiones, definiciones y producciones de sentido que integran la construcción siempre abierta de lo común en la educación escolar, la cual se enmarca de forma más amplia en discusiones respecto de las relaciones entre escuela y desigualdad social.

Palabras clave: educación primaria; desigualdad social; trabajo docente; posición docente; lo común

\section{Teaching positions and constructions among the common against inequality in Argentina}

\section{ABSTRACT}

In this article I will try to account for the senses around the common occurring in teaching positions that teachers of three public primary schools in the province of Buenos Aires, Argentina, build in situations of social and educational inequality, inquiring about meanings they attribute to their work, and the problems and challenges that they formulate around it. These schools work with students living in poverty, in territories crossed by various forms of inequality. The idea of the common in schooling has a fixed and unchanging content, but is made up of temporary significances why disputes, which involved, among others, the official pedagogical discourse and the various appropriations by teachers. In the

* Este artículo presenta una serie de resultados de la investigación realizada en el marco de mi tesis de doctorado en educación "Regulaciones del trabajo de enseñar en la provincia de Buenos Aires: posiciones docentes frente a la desigualdad social y educativa”, dirigida por la Dra. Myriam Southwell y desarrollada en la Facultad de Filosofía y Letras de la Universidad de Buenos Aires.

Doctor en Educación por la Universidad de Buenos Aires. Investigador Asistente del Consejo Nacional de Investigaciones Científicas y Técnicas en el Instituto de Investigaciones en Humanidades y Ciencias Sociales (CONICET-Universidad Nacional de La Plata). Docente de la Universidad Nacional de La Plata y la Universidad de Buenos Aires. Nacionalidad: Argentina. E-mail: alevassiliades@gmail.com 
daily construction of responses to inequality, teachers develop reflections, definitions and productions of meaning that participate in the construction of the common in schooling processes, which are framed in discussions regarding the relationship between school and social inequality.

Keywords: primary schooling; social inequality; teaching work; teaching position; the common

\section{Introducción}

La noción de lo común ha sido una de las estructurantes del modo en que se pensó la escolarización en Argentina y ha estado ligada a la manera en que se plantearon los vínculos entre el trabajo de enseñar y la cuestión de la desigualdad. En los orígenes del sistema educativo, "lo común" estuvo asociado al presunto carácter "universal" de la escuela y a su tendencia homogeneizadora, a partir de la cual se asumía su carácter inclusivo y se afirmaba la equivalencia entre aquélla y la idea de igualdad (Dussel, 2004; Southwell, 2006). La escuela era "igual para todos" " porque supuestamente trataba a todos de la misma manera y a ellas debían acceder todos por igual. Lo común fue, así, entendido como lo mismo (Terigi, 2008), situación que se consolidó cuando, descubriéndose que el mero acceso no resuelve la cuestión de la igualdad, se planteó la necesidad de que todos alcanzaran los mismos resultados de aprendizaje. La escuela supuso, así, una definición específica de "lo común" y una acción sobre él. Esa misma definición implicó la fijación provisoria de un "afuera de lo común", donde quedaban excluidos aquellos elementos y pautas culturales consideradas de menor valor, peligrosas o amenazantes, y que no entraban en el recorte cultural que la escuela transmitía y que era significado como común. La definición de este común supuso la producción de diferencias, jerarquías, negaciones y exclusiones (Diker, 2008), tanto de sujetos como de contenidos culturales.

I Como señala Diker (2008) a partir del análisis de la universalidad que realiza Badiou, se constituye para la educación escolar una tautología según la cual, dado que lo que ella transmite es "lo común”, se dirige a todos, y porque se dirige a todos, eso que la escuela transmite es sinónimo de "lo común". 
La idea de lo común en la escolarización no tiene un contenido fijo e inmutable, sino que está compuesto de significaciones provisorias por las que se libran disputas. Éstas integran las luchas por la hegemonía en términos de fijar las articulaciones de sentido en torno de lo común en la educación escolar. En este marco, lo común no es "lo mismo" sino una construcción que intenta llenar una vacuidad de significados de maneras diversas. Como algunos analistas han enfatizado, el currículum "común” no ha sido tradicionalmente aquel que incluyó la totalidad de los saberes o expresiones de diversas fuentes de conocimiento sino el que compone el punto de vista de los sectores dominantes y excluye el de los menos favorecidos (Connell, I997; Terigi, 2008). Una discusión central en torno del despliegue de la educación escolar es qué porción de la cultura se define como fondo compartido para todos y cómo se juega, allí, la construcción de lo común y la cuestión de la pluralidad de identidades en articulación con los modos en que la transmisión cultural procura instituir formas de vida, lenguajes, códigos y ciudadanías (Birgin y Serra, 20I2).

En este artículo intentaré dar cuenta de los sentidos en torno de lo común que tienen lugar en las posiciones docentes (Southwell y Vassiliades, 20I4) que maestras de tres escuelas primarias públicas de la provincia de Buenos Aires, Argentina, construyen frente a situaciones de desigualdad social y educativa, indagando acerca de los significados que atribuyen a su trabajo, y los problemas y desafíos que se formulan en torno de él. Estas escuelas trabajan con estudiantes que viven en condiciones de pobreza, en territorios surcados por diversas formas de la desigualdad. En la investigación que dio lugar a este artículo, no he partido de un significado fijo de lo común para el análisis, para luego indagar qué hacen los maestros con ello. Por el contrario, en la construcción cotidiana de respuestas frente a situaciones que identifican como del orden de la desigualdad, los docentes desarrollan reflexiones, definiciones y producciones de sentido que integran la construcción siempre abierta de lo común en la educación escolar, la cual se enmarca de forma más amplia en discusiones respecto de las relaciones entre escuela y desigualdad social. 


\section{"Contra viento y marea": sobre la enseñanza obstinada y los modos de pensar la inclusión y lo común}

Un aspecto de las posiciones docentes frente a la desigualdad social y educativa que fue posible registrar en el trabajo de campo es la asunción de que lo común tiene que ver con la posibilidad de acceder al conocimiento escolar, aquél legitimado en el currículum, y que esa construcción, en tanto posibilidad de inclusión, requiere que se otorgue un lugar central a la enseñanza como tarea central del trabajo docente. Estos elementos se incorporan a lo que resulta posible hacer para enfrentar los rasgos de la desigualdad educativa identificados por los docentes, relativos a la discontinuidad en la asistencia a las instituciones educativas, la repitencia, la sobreedad y el mal llamado "abandono" escolar. Lo común es así "lo mismo" para todos, entendiendo por ello la enseñanza del conocimiento escolar al conjunto de los alumnos y alumnas. Como intentaré mostrar, esta asunción implica también la noción de que los estudiantes son "lo mismo" y la negación de las diferencias entre ellos y respecto de los saberes que portan, aunque no así en relación a sus trayectorias escolares.

Parafraseando a una docente, un aspecto en el que esta posición se evidencia es el sostenimiento "contra viento y marea" del trabajo de enseñanza de los contenidos curriculares en las escuelas que integraron el trabajo de campo. He denominado a esta posición con la categoría "enseñanza obstinada", intentando dar cuenta de un modo específico de asumir esta tarea y el trabajo docente que encuentra importantes similitudes con investigaciones previas relativas a la tarea de enseñar en contextos de pobreza (Redondo, 2004). Con recursos de la gestión escolar o bien con elementos propios, las docentes procuran que la mayor cantidad de tiempo áulico sea destinada al aprendizaje del conocimiento escolar. La prioridad dada a este último incluye la asunción de que resulta una herramienta fundamental en relación a la posibilidad de tornar más igualitarios los futuros de sus alumnos. Las tres escuelas comparten el haberse propuesto elevar los niveles de aprendizaje de los grados menores como parte de las iniciativas institucionales que desarrollan. 
Las docentes perciben que la implementación de las iniciativas institucionales para fortalecer la transmisión de contenidos escolares permitió situar a la enseñanza en el centro de la escena y desplazar a la contención afectiva a un segundo plano. Esta última se carga de una valoración negativa y es situada en relación al pasado de "desborde" que quiere dejarse atrás y en oposición a la tarea de enseñar, aun cuando en las posiciones docentes convivan superponiéndose o complementándose. Varios docentes se esfuerzan por explicar que su trabajo no consiste en contener sino en enseñar, presentando estas actividades en términos excluyentes y dando cuenta de la configuración de dos series opuestas. Una de ellas articula la enseñanza "obstinada" de contenidos escolares con el presente, con la noción de dar "lo mismo" a "todos" (que son, también, "lo mismo"), con la idea de que "lo escolar" consiste en el desarrollo de esa tarea de enseñanza, y con la premisa de que ella posibilitará futuros más igualitarios en los estudiantes. La otra serie, construida en torno de la "contención", queda ligada al pasado, la asistencialidad, las situaciones de "violencia", la afectividad y la idea de que la escuela se había convertido en un ámbito "no escolar". Aunque presentadas como dicotómicas en las concepciones de los docentes, intentaré mostrar cómo ambas series se interrelacionan de manera compleja -y hasta a veces paradójica- para componer las posiciones docentes.

La "centralidad de la enseñanza" constituye un eje central del discurso pedagógico oficial en el período 2003-20I5 (Vassiliades, 20I4) y parece inscribirse en las posiciones docentes que fue posible relevar en la investigación. Esta prioridad otorgada a la enseñanza del conocimiento escolar permite a los maestros resignificar su trabajo en escuelas a las que asisten sectores que viven en condiciones de pobreza, discutiendo aquellas posturas que ven en la "contención afectiva" o la asistencia social un límite infranqueable para llevar adelante aquella tarea. Una expresión de ello es el modo en que, de forma recurrente en recreos y encuentros en los pasillos de las escuelas, los docentes intercambian respecto de lo positivo que es para ellos sentir que "están enseñando", y desarrollan discusiones respecto de hasta qué tema llegar y de qué modo poder avanzar en la progresión de contenidos con determinado grupo. El trabajo por proyectos que procuran hilvanar una interdisciplinariedad entre 
las asignaturas permite, también, tornar explícito el trabajo con los contenidos escolares a través de una abundante producción por parte de los estudiantes. Las muestras organizadas trimestralmente por las escuelas intentan plasmar los aprendizajes alcanzados por los alumnos y suelen ser ocasiones muy ponderadas por los docentes. En una muestra literaria organizada por una de las escuelas y titulada "Un día de fantasía” acontecía lo siguiente:

"...La muestra sorprende por la cantidad de material en exbibición. El patio interno está poblado de alumnos que caminan o corren, muchos de ellos acompañados por sus familias. En el centro, sobre pupitres puestos en círculo, se exbiben maquetas que representaban cuentos infantiles -Los Tres Chanchitos, Blancanieves, Caperucita Roja- que son acompañados de un cartel que señala que fueron realizados en el taller de plástica. Al mismo tiempo, algunas carteleras acompañan estas producciones, como una en la que babía formas geométricas de un espejo -el de la bistoria de Blancanieves- que los chicos trabajaron en la clase de matemática. Un aula entera fue convertida en bosque armando árboles de papel y calculando las proporciones entre las copas y los troncos, según relata orgullosa una docente a los padres de una alumna, que parecen escucharla con atención (...).

Las aulas están ambientadas de acuerdo a este proyecto, que fue trabajado por los seis grados de la escuela y aglutina las diversas asignaturas. Una de las aulas tiene un cartel en la entrada que la define como el "Museo de la Antigüedad". Dentro de ella bay una maqueta del Partenón, otra del caballo de Troya, y carteleras con el relato de la bistoria de Troya, dibujos de guardas griegas e información sobre "la aparición del bombre", comentando algunos aspectos sobre la evolución de la especie bumana. Hay, además, una maqueta sobre Teseo y el Minotauro. En otra aula se bace repetidamente una representación teatral a cargo de los alumnos. Afuera de este salón me cruzo con una maestra que, luego de saludarme, me comenta con entusiasmo acerca de la cantidad de producciones que realizaron sus alumnos y cómo ellos se interesaron por la bistoria de Egipto y por la mitología griega, acercándose a preguntar dudas o trayendo información. Resalta que esto antes no ocurría y que, de no ser por el marco de trabajo que les dio el proyecto sobre literatura, ello no babría sucedido. Otra maestra, que escucha esta conversación, se suma relatando el trabajo de sus alumnos en el área de Prácticas del Lenguaje. Son docentes que se muestran muy orgullosas con lo que ban becho sus estudiantes" (registro en muestra literaria, escuela I). 
Orgullo y entusiasmo se entraman con la enseñanza del conocimiento escolar a los estudiantes. Para las maestras ${ }^{2}$, la desigualdad educativa es entendida en términos del bajo nivel de aprendizajes y lo mejor que podría acontecer a los estudiantes es la posibilidad de apropiarse del conocimiento legitimado en el diseño curricular. La institución de algo del orden de lo común está, así, íntimamente ligado al acceso a dicho conocimiento, el mismo para todos y todas. El orgullo de las maestras que reseña el registro reside, particularmente, en la posibilidad que la muestra literaria habría brindado a sus estudiantes para aproximarse a otros universos culturales, distintos de aquéllos más cercanos y conocidos para ellos. En este sentido, comparten la asunción de que es tarea de la escuela acercarlos (de modo "común”) a esas otras formas culturales, y que su conocimiento será un modo de promover futuros más igualitarios en las trayectorias de sus alumnos. La siguiente situación, observada en una de las primeras recorridas institucionales, quizás permita ilustrar los vínculos que los colectivos docentes de las escuelas intentan construir con el conocimiento escolar y el horizonte de expectativas respecto de las relaciones que esperan que sus alumnos desarrollen en relación a él:

"Era un día algo diferente en la escuela, porque la inspectora de nivel se ballaba de visita. Eso dificultó realizar alounas observaciones previstas en las aulas, pero de todos modos fue posible sostener algunos intercambios con las docentes. La inspectora ingresó y permaneció algo más de media hora en el aula-taller de prácticas del lenguaje, donde los alumnos de sexto grado estaban trabajando la Leyenda del Dragón Galés a partir de un libro -escrito por un maestro- que la docente del área babía traído a sus estudiantes. Al salir de alli, la inspectora se dirige a la dirección de la escuela, y luego de un breve intercambio con la directora se retira de la institución. Esta última sale de su oficina y me comenta que la inspectora le objetó el trabajo sobre la Leyenda del Dragón Galés por ser 'lejana a la cultura de los chicos', y enfatizó en que era importante trabajar lo próximo a ellos, como por ejemplo las leyendas guaraníes. Enojada, la directora dice que le respondió que para los chicos era tan lejana la Leyenda del Dragón Galés como las de los guaranies, y que si se tienen que restringir a lo próximo, las maestras se la pasarían bablando de

2 La utilización del femenino en "maestras" responde al hecho de que la totalidad de las docentes en las tres escuelas son mujeres. 
la cumbia. Y enfatiza 'A mí el diseño curricular me pone que yo tengo que enriquecer su acervo cultural partiendo de lo que a ellos les atrae. Abora, no es quedarse enseñando eso que les atrae y nada más. $Y$ dar por descontado que a ellos les atrae la leyenda guaraní es un prejuicio. ¿No les enriquecí en este caso yo su acervo cultural con una leyenda de la Patagonia como la del dragón galés? Lo demás es prejuicio '." (nota de campo y conversación informal con la directora, escuela I)

La escena en torno de la leyenda del Dragón Galés condensa la posición docente en torno de la enseñanza del conocimiento escolar como un elemento que integra aquello del orden de "lo común" que es "lo mismo" y "para todos". La discusión que la directora sostiene con la inspectora remite a uno de los debates más importantes en el campo de la educación en el análisis de los vínculos entre escuela y desigualdad social: que la escuela amplíe el universo cultural de los niños aproximándolos a otras expresiones que jamás conocerían si no fuera por la escuela, o bien que las instituciones educativas partan de y trabajen sobre aquello conocido y próximo a la "realidad" de sus alumnos para fortalecerlo e introducir una disputa en la jerarquía cultural que suelen encabezar los conocimientos "escolares". Si bien no es posible conocer si la intervención de la inspectora se ubica en estas coordenadas o contiene esas aspiraciones, sí supone una opción por la incorporación de contenidos próximos al universo cultural de los alumnos de la escuela -las leyendas de los guaraníes-, que los docentes descartan en pos de expresiones culturales más lejanas -la Leyenda del Dragón Galés-, a partir de la apropiación que realizan de las prescripciones del diseño curricular. De este modo, las docentes participan de las discusiones respecto de los vínculos entre escuela y desigualdad social desde el punto de vista del problema del conocimiento. En la apuesta a la enseñanza del saber legitimado en el currículum hay un modo en que las posiciones prefiguran cómo trabajar con dicha desigualdad y una valoración de las potencialidades de los universos culturales no conocidos por los estudiantes.

En la discusión en torno del Dragón Galés se despliegan concepciones docentes respecto de qué es posible hacer, desde la escuela, con las situaciones de desigualdad y sobre el papel del conocimiento escolar en el desarrollo de esas estrategias. En esas concepciones, 
parece primar la idea de que la igualdad equivale a ampliar los horizontes a cada uno de los alumnos, aunque sin discutir el status del conocimiento escolar ni considerar las diferencias que cada uno de ellos porta. No se incorpora a las escenas pedagógicas lo que cada estudiante puede traer. Si consideráramos la dimensión bidimensional de la justicia propuesta por Fraser (2000), podría decirse que en las posiciones docentes de las que estoy dando cuenta hay una opción por la redistribución, sin una consideración equivalente por el reconocimiento de los alumnos. La serie en torno a la "enseñanza obstinada" que antes presente incorpora como elemento el hecho de que la igualdad es equivalente de ofrecer algo del orden de los conocimientos que resultan lejanos a los alumnos, y que ello resulta democratizador. La articulación entre enseñanza (obstinada), conocimiento (escolar y lejano a los alumnos), igualdad equivalente a "dar lo mismo", lo común (representado por la enseñanza de lo mismo), y una concepción homogénea de los alumnos (que son "lo mismo" y no poseen diferencias), parece organizar las posiciones docentes de las que estoy dando cuenta.

En efecto, las iniciativas institucionales registradas comparten la configuración de una relación con la cultura que evita la incorporación de prácticas que son más cercanas al horizonte cultural de los estudiantes. Las docentes no suelen optar por trabajan los contenidos desde lo que los niños conocen, sino que procuran ofrecerles la posibilidad de entrar en contacto con herramientas y producciones propias de universos culturales que habitualmente les son vedados. Pese a ello, las docentes suelen poner en juego códigos comunes y conocidos para los estudiantes que hacen posible la comunicación a modo de estrategia de trabajo. La apuesta a que aprendan supone la apertura a posibles emergentes en el aula para, a partir de ellos, abordar los contenidos que estaban previstos:

"Se trabaja mucho a partir de lo que ellos tienen mucho interés (sic) y vos tenés que ser muy abierto de cabeza para saber qué es lo que a ellos les interesa y meter todo adentro del contenido que tenés que dar. Si ellos dicen 'Señorita, vamos a bacer mate'... y sí, jhagamos mate! Entonces veo a ver qué puedo meter en matemática para bacer mate, de lo que tengo que dar en clase. Hay que estar muy despierto y muy abierto. Te bablo de matemática porque es lo 
que yo doy, pero seguramente en Lengua y en Ciencias pasará exactamente igual" (entrevista a un docente de segundo ciclo, Escuela del Programa).

A diferencia de lo relevado por otras investigaciones sobre el trabajo docente en condiciones de pobreza (Achilli, 2010), la predisposición y atención que los maestros tienen hacia las temáticas que interesan o proponen los alumnos no interrumpen el proceso de la clase ni tampoco la dejan inconclusa, sino que son incorporadas en función de los contenidos que vienen siendo trabajados. Sin embargo, y como señala la autora citada, la cotidianidad escolar de las escuelas que formaron parte del trabajo de campo está imbuida de la idea de que el niño es poseedor de saberes "extraescolares", los cuales son apropiados en forma previa o simultánea a los aprendizajes en el contexto escolar, cuya incorporación en los procesos pedagógicos puede resultar supuestamente positiva para lograr el aprendizaje de los contenidos curriculares.

Pese a la apertura a estos emergentes, los colectivos docentes de las tres escuelas comparten la posición de no mimetizar la propuesta de enseñanza con lo que se entiende que es propio del horizonte cultural de los niños (Diker, 2007). En las escuelas se utilizan recursos atractivos, visuales y musicales en el desarrollo de los proyectos y para la preparación de las muestras, pero también otros que suponen otros registros y lenguajes, con la intención de que los niños puedan apreciar y producir elementos culturales que ponen en juego estos otros recursos. La intención de ampliar el campo cognoscitivo de los alumnos estructura las propuestas pedagógicas en el contexto de los proyectos institucionales. Siguiendo a Diker (2007), no parece haber un prejuicio según el cual a los niños de sectores populares habría que "entretenerlos" todo el tiempo con recursos visuales y musicales cercanos a sus pautas culturales. Por el contrario, se incorporan una serie de técnicas vinculadas con el arte que forman parte de los contenidos de enseñanza:

"Si vos pretendés una formación académica o tradicional -yo te doy el libro y vos estudiás el manual- estos chicos fracasan todos. Vos tenés que buscar la estrategia y la manera para que el chico aprenda, baga y se sienta que es capaz. Porque si no fracasás vos, fracaso yo como docente, fracasa la escuela, 
cerremos y nos vamos cada uno a sus casas. El becho de que los chicos vean colgados sus cuadros y que los padres se quedaran. . las caras de esos chicos. Lo que ellos no se dan cuenta por abí es que para llegar a ese cuadro trabajaron un montón de contenidos de matemática, y de plástica, y de inglés, y de lengua - porque bicieron la biografía de Petorutti, investigaron la técnica, o sea cuántos contenidos se trabajaron para ese producto-. Impensado. Los folletos de la muestra los bicieron en inglés. Y como eso, muchas cosas" (entrevista a docente de segundo ciclo, escuela 2).

En la serie en torno de la "enseñanza obstinada" de la que aquí estoy dando cuenta, la posición docente se corre de una intervención reducida a la asistencia material (la provisión de alimentos, cuidados de la salud, y todo aquello que defina la "contención" en sentido estricto), y se dirige a poner a disposición herramientas simbólicas y expresivas que abren la posibilidad de que los niños y niñas puedan producir y aportar al trabajo en el aula. Los espacios expresivos que habilitan las iniciativas institucionales posibilitan que los estudiantes puedan comunicar sus modos de sentir y pensar en relación con las temáticas trabajadas en las diversas áreas. Sin embargo, ello no implica la renuncia, por parte de las docentes, a toda forma de intervención vinculada con las producciones de los alumnos. Por el contrario, las maestras intervienen recurrentemente para corregir la ortografía o realizar sugerencias respecto de las formas de expresión escrita o plástica:

"En la clase de ciencias de segundo ciclo, la maestra interroga a los alumnos sobre la permeabilidad y la impermeabilidad y le pregunta a un alumno en qué caso no pasa el agua. Un alumno le responde. La maestra pide que copien pronto del pizarrón y que bagan el ejercicio que escribió allí. Un alumno dice: 'Lo bago así nomás' y la maestra responde: 'A Así nomás dijiste?'. El alumno le contesta que 'es re difícil', y la maestra le dice que es importante bacerlo para una muestra. A otro alumno le pide que le lleve el cuaderno y le corrige errores de ortografía. Dirigiéndose al resto de la clase, les pide que cuiden la escritura: "chicos es muy importante que prestemos atención a cómo escribimos y que escribamos bien". Pide a una alumna que le lleve el cuaderno y se siente a su lado para ver juntas la realización del ejercicio. Al terminar, se levanta y pasa por los bancos señalando aspectos a corregir en la escritura" (registro de observación de clase de ciencias, escuela 3). 
Como puede observarse, enseñar se torna equivalente de transmitir el conocimiento escolar, aquél validado socialmente y legitimado en el diseño curricular, y también de acompañar a los alumnos en la organización de dicho conocimiento, en particular a través de las instancias de producción y de realización de muestras que antes he analizado. Parece asumirse que la posibilidad de modificar la relación con el saber podría impactar en la percepción de los alumnos sobre sí mismos y sobre sus posibilidades de futuro, habilitándose otros horizontes posibles. Esta relación con el saber no se reduce al dominio de un saber específico, sino que abarca también el modo en que un sujeto se posiciona frente a él y sus posibilidades de aprender y de hacer. Junto con ello, el proyecto institucional aspira a la construcción de unas formas de relación con el saber que permitan las posibilidades de aproximación a otros saberes fuera de ella. En este sentido, desarrollan una "enseñanza obstinada" de los contenidos escolares, lo cual supone que ella debe constituir el eje del trabajo pedagógico que desarrollan las docentes.

¿Qué premisas implícitas o relativamente explícitas se entrecruzan e hilvanan en forma de trama para sostener que la promoción del acceso al conocimiento escolar se vincula con algo del orden de lo justo, lo igualitario o de lo democrático? La historia del trabajo docente en Argentina, y en particular el modo en que el discurso normalista posicionó en un lugar central lo que una escuela tiene para ofrecer como sinónimo de una búsqueda de mayor igualdad, juega un papel central en dicha construcción. Sin embargo, ella es también tributaria del modo en que, en los últimos años, parece haberse resituado la enseñanza como tarea fundamental de la escuela, en oposición a la desconsideración que de ella hicieron los discursos pedagógicos hegemónicos durante el período de la última dictadura y la década del '90, que establecieron una idea de escolarización "a demanda" (Pineau, 2007). Dicho de otro modo, la valoración de la distribución del conocimiento escolar que estamos analizando encuentra su condición de posibilidad en la historia del trabajo docente en nuestro país -aun cuando en sus orígenes éste haya tenido un cariz moralizante (Alliaud, I993; Birgin, 1999)-, y en la actual producción y circulación de discursos respecto de la construcción de una posición docente frente a situaciones del orden de la desigualdad. 
En este sentido, la valoración del conocimiento escolar supone la presencia de una determinada jerarquía cultural -es válido transmitir los contenidos "escolares", en detrimento de otros que permanecen en un lugar de no visibilidad-como así también la asunción de que la enseñanza del mismo habilita horizontes de posibilidad distintos para los alumnos y alumnas, considerando lo que ellos tienen para aportar a la relación con dicho conocimiento.

Esta tensión habilita una variedad de posiciones, que se extienden en un arco que va desde el sostenimiento de la enseñanza del conocimiento escolar, sin apertura a lo que los alumnos tengan para traer a la clase, hasta aquellas que intentan atender a esto último, pero sin renunciar al trabajo de enseñar los contenidos previstos en el currículum. En este sentido, las iniciativas parecen dar cuenta de una suerte de "límite escolanovista", según el cual el énfasis en la producción de los alumnos y la centralidad en lo que ellos tienen para aportar -dos principios específicamente propios del movimiento de la Escuela Nueva- no afectarían la prioridad otorgada a la enseñanza del conocimiento escolar. Dichos principios terminan, así, subordinándose a esa lógica, como ha sucedido con las posiciones escolanovistas hegemónicas a lo largo de la historia educativa argentina desde la década del '20 del siglo XX.

Asimismo, las iniciativas registradas por el trabajo de campo parecen apuntar a tornar posible que los niños se vuelvan sujetos alumnos y habiten la escuela como tales. La noción de igualdad que subyace a ellas no implica la posibilidad de educarse desde y en sus propias diferencias, sino fundamentalmente la distribución de las mismas oportunidades de disponer de una cultura homogénea, la cultura escolar. En este sentido, un matiz que poseen estas innovaciones que buscan democratizar el acceso al conocimiento es que la redistribución que operan supone que hay quienes podrían ocupar una posición inferior por no poseer determinados elementos culturales, los relativos al conocimiento escolar que la escuela busca distribuir. Ello afecta a que todos los estudiantes puedan ser considerados como iguales, con derecho a preservar su identidad y sus tradiciones culturales, como así también su propia voz. Los docentes entrevistados comparten el ubicarse en la posición de 
educadores que saben y pueden transmitir un conocimiento a aquellos ubicados en una posición culturalmente menos valiosa y de ignorancia. La igualdad es, así, un horizonte al cual trasladarse permanentemente desde esa situación de inferioridad.

Estas posiciones conjugan aspectos pastorales y normalistas aunados en torno de la idea de transmitir una cultura "superior", "más alta", que la que poseen sus alumnos, como así también una consideración ético-política respecto del derecho de los alumnos a que otros saberes les sean acercados y puestos a disposición. En este sentido, la posición docente sobre la "enseñanza obstinada" alberga sentidos y principios contrapuestos que habitan los discursos pedagógicos de los sujetos maestros y maestras. Ella supone un "enseñar pese a todo", sobreponiéndose a los problemas y dificultades cotidianas, pero también un "enseñar pese a todos" en términos de hacerlo a pesar de las diferencias culturales de los estudiantes, silenciadas en la obstinación por transmitir el conocimiento escolar. Esta negación parece constituir, en el caso de las docentes, una condición de posibilidad para que la enseñanza - del modo específico en que ellas la piensan- tenga lugar. La asociación entre lo común y lo mismo sostiene, así, la equivalencia entre trabajo docente y enseñanza de contenidos escolares.

\section{Lo común y el trabajo con los estudiantes: sobre homogeneidades no problematizadas}

Otra noción de lo común que atraviesa a las posiciones docentes es la posibilidad de que todos los estudiantes se integren al trabajo "común”, que se propone como compartido en el aula. Las propuestas ensayadas por las escuelas que integraron el trabajo de campo ponen el énfasis en la atención a la diversidad y la individualidad, si bien no alteran el modelo organizacional del aula graduada. Aun así, las innovaciones, proyectos e iniciativas desarrolladas se orientan a habilitar la posibilidad de que todos y todas puedan aprender los contenidos prescriptos por el diseño curricular, con una serie de matices. Esta intención se plasma en el desarrollo del trabajo con el grupo total en las aulas, la habilitación de diversos modos de resolución de tareas y el desarrollo de estrategias para hacer que los 
alumnos sean partícipes de aquello que es del orden de "lo común" y para todos.

En relación al sostenimiento del trabajo con el grupo total dentro de las aulas, las docentes no constituyen subgrupos sino que desarrollan su tarea con el conjunto de los estudiantes. En las tres escuelas, el trabajo con el grupo total no impide que se habiliten diversos modos de resolución de tareas. En las observaciones de clases ha sido habitual ver que algunos alumnos realizan ciertas actividades de un modo diferente al previsto por la consigna y ello, en la mayoría de los casos, es ponderado por los docentes con frases tales como "lo hizo distinto pero está súper bien también", "no es tal cual lo que pedía la consigna pero está muy bien igual”, o "miren chicos, acá hay otra manera válida de resolver la consigna”. Al mismo tiempo algunos docentes generan una actividad específica alternativa a la planteada para que algunos alumnos puedan incluirse y desarrollar su trabajo escolar. Estas iniciativas plantean un modo de resolver las llamadas "dificultades de aprendizaje", con la intención principal de que los alumnos "no se sientan frustrados". En algunos casos, esta posición también incluye la lectura en voz alta de las consignas o los problemas matemáticos para los grupos en los que hay alumnos que aún no saben leer, o llevándolos en fotocopias y proponiéndoles su resolución colectiva, como modo de encontrar una resolución a esa dificultad.

Por otra parte, los docentes también desarrollan una serie de estrategias que ellos conciben como destinadas a "cubrir" o "llenar" aquello que los alumnos no tienen, con la intención de que éstos sean partícipes de ese lugar de "lo común" constituido por aquellos saberes que todos deberían adquirir y tener. La apuesta a que los estudiantes aprendan incluye también modificaciones en la lógica de trabajo por proyectos de las tres instituciones, en la que se introducen algunas interrupciones para abordar contenidos específicos que algunos grupos no tienen. Al igual que sucedía con los tiempos y espacios escolares, el tipo de trabajo en el aula -por proyectos o a través de una clase más tradicional- aparece subordinado a las necesidades de aprendizaje de los alumnos. Se trata de "hacer todo lo que se pueda" cuando los alumnos "tienen baches", y ello incluye 
situaciones de enseñanza más directivas. En un intercambio en una jornada institucional, dos docentes conversaban sobre lo siguiente:

DI: "Es eso que dice ella... tenés que enseñarles mecánicamente porque lo necesitan y tienen que saber el mecanismo de la división. No me voy a explayar como en el primer ciclo a dársela desde otro lado. Porque no te alcanza el tiempo, porque tenés que acercar todo lo más que se pueda.

D2: Eso es lo que te permite el taller. Yo no lo voy a trabajar como taller, tengo que dar una clase magistral de división. Yo les voy a enseñar a dividir, pero también les voy a elaborar en el taller todo lo que incluye esa división. Pero yo en esto no me puedo detener porque necesito que sepan todo lo otro, porque están en cuarto. Se pierde esa parte de taller que es la que adquiere el chico de tercero, el de aprender jugando, el de aprender repartiendo, el de aprender utilizando las palabras, el de aprender el lenguaje matemático correspondiente. No queda otra que agarrar eso que no vieron el año pasado y darlo como clase magistral, que lo aprendan, y seguir para adelante con lo otro en el taller" (intercambio entre docentes en una jornada institucional, escuela 2).

"Nosotras tratamos de que el nivel sea cada vez un poco más alto, que no sea como era antes que se nivelaba para abajo. Tratamos que nivele para arriba. O sea, yo les voy a enseñar a dividir, pero no para que se queden con la división sino para que sepan bacer cosas nuevas y más complicadas. Antes vos nivelabas para abajo. . que sepa dividir y abí nos quedábamos. $O$ a veces ni siquiera eso, una se quería matar, cómo no van a saber dividir en sexto grado? Y no, no sabian dividir. Hoy saben dividir y van a saber los decimales, fracciones y todo lo demás" (entrevista a docente, escuela 3 ).

El corrimiento respecto de las estrategias didácticas que vienen utilizando persigue el objetivo de "enseñar todo lo que se pueda" y "elevar el nivel", propósitos que trascienden lo estrictamente metodológico y se ubican en las coordenadas de discusiones pedagógicas relativamente recientes. Las pedagogías hegemónicas durante la última dictadura y la década del '90 en la provincia se caracterizaron por desarrollar una pedagogía de la espera (Pineau, 2006) que sostuvo la necesidad de retacear el trabajo de transmisión cultural y adaptarlo a los procesos madurativos - entendidos como 
individuales- de los estudiantes. La enseñanza, en este marco, debía correrse de un lugar central y ubicarse en el plano de la "guía" de los alumnos, cuyos aprendizajes cabría solamente esperar a medida que se produjeran avances en la maduración. Propuestas como las que aquí estoy analizando, que otorgan un lugar central a la enseñanza y la desarrollan sorteando obstáculos e imaginando estrategias pedagógicas para hacerlo, discuten y revisan aquellas pedagogías recientes. En estos debates intervienen también los sentidos que son puestos a circular por las políticas oficiales actuales y que abogan por el sostenimiento de la "centralidad de la enseñanza" en las escuelas. Las iniciativas que desarrollan los docentes dan cuenta de las apropiaciones de estos sentidos.

Por otra parte, las posiciones docentes también incluyen presencias y ausencias de tematizaciones respecto de lo que los alumnos tienen en común. En las consideraciones respecto de las tensiones entre lo particular y lo común, la cuestión de la homogeneidad o heterogeneidad de los estudiantes no es problematizada por las docentes de la Escuela del Proyecto. Sí es incluida en el relato respecto de cómo la escuela se convirtió en lo que es, al enfatizar que en los últimos años la matrícula se hizo cada vez menos diversa y más parecida entre sí en términos de perfil socioeconómico, siguiendo los parámetros de lo que algunos analistas han denominado fragmentación educativa (Tiramonti, 2004; Kessler, 2002). El hecho de que los alumnos se parezcan entre sí en términos de su procedencia social no constituye, desde las posiciones que construyen las docentes de la escuela, un problema del orden de la desigualdad educativa y por el que cabría hacer algo para modificarlo, sino una realidad con la cual trabajar diariamente.

A la invisibilización de la ausencia de heterogeneidad en procedencias sociales de los alumnos debe agregarse otra operación: la asunción de que los alumnos "son iguales entre sí" y que no poseen diferencias. Esta idea, que supone una concepción de que los estudiantes son "lo mismo" estaba ya presente en el modo en que se planteaba la enseñanza de los contenidos escolares al grupo de estudiantes. Aquí adopta otra inscripción, relativa a la supuesta homogeneidad de los alumnos al ser comparados entre sí. Ella se incorpora a la serie trazada 
en torno de la enseñanza obstinada: el trabajo docente equivale a enseñar (los contenidos escolares), y enseñar queda asociado a la reducción de la alteridad a lo mismo, como operación anterior a la enseñanza y como una aparente condición para que ella tenga lugar.

"Son todos iguales porque todos tienen los mismos problemas". Las docentes perciben la homogeneidad entre sus alumnos como un problema específico que se diferencia de aquél que es del orden de la desigualdad, en el sentido de que implica que "todos tienen problemas" o que "el nivel es bajo en todos", pero no en términos de que en la escuela no están confluyendo alumnos de procedencias heterogéneas. La mirada crítica acerca del bajo nivel promovió el sostenimiento de que había que elevarlo en el equipo docente, aunque la invisibilización del problema de la homogeneidad como un problema del orden de la fragmentación y de la desigualdad se tradujo en la ausencia de iniciativas para revertirlo. Se trata de pibes diferentes que las docentes ven como iguales.

\section{A modo de cierre}

A lo largo de este artículo me propuse dar cuenta del modo en que las configuraciones en torno de lo común constituyen rasgos nodales de la construcción de posiciones docentes frente a la desigualdad social y educativa. Ellos implican una multiplicidad de relaciones caracterizadas por las paradojas y las diversas articulaciones que dan cuenta de su provisoriedad en tanto construcción siempre en curso. La consistencia, la linealidad y la simplicidad no son atributos de esa composición. Ella está siempre rodeada de elementos residuales y emergentes que amenazan permanentemente la estabilidad de su configuración y que son relativos a cómo se van configurando las posiciones docentes analizadas. Las reapropiaciones de la historia de la regulación del trabajo de enseñar por parte del sujeto docente, los múltiples vínculos con los saberes y su enseñanza, las relaciones con las nuevas generaciones, configuran un magma inestable y difícil de asir, en permanente movimiento y nunca solidificado.

Las definiciones en torno de lo común constituyen un elemento inescindible de la posición docente que los maestros y maestras 
construyen, y a la vez son consecuencia de esa construcción. En este proceso de configuración mutua, los docentes participan de disputas por fijar temporalmente articulaciones de sentido en torno de lo común en la educación escolar. Ello conlleva un movimiento de constitución -también provisoria- de un universal que implica la producción de diferencias y relaciones relativamente igualitarias o desiguales entre sujetos y saberes.

\section{Referencias bibliográficas}

Achilli, E. (2010). Escuela, familia y desigualdad social. Una antropología en tiempos neoliberales. Rosario: Laborde Editor.

Alliaud, A. (1993). Los maestros y su bistoria: los orígenes del magisterio argentino. Buenos Aires: Centro Editor de América Latina.

Birgin, A. (I999). El trabajo de enseñar. Entre la vocación y el mercado: las nuevas reglas del juego. Buenos Aires: Troquel.

Birgin, A. y Serra, S. (2012). Cultura y formación docente: viejas fórmulas y nuevas encrucijadas. En A. Birgin (comp.) Más allá de la capacitación. Debates acerca de la formación de docentes en ejercicio (pp. 233-256). Buenos Aires: Paidós.

Connell, R. (I997). Escuelas y justicia social. Madrid: Morata.

Diker, G. (2007). ¿Es posible promover otra relación con el saber? Reflexiones en torno del proyecto DAS. En R. Baquero, G. Diker y G. Frigerio (comps.) Las Formas de lo Escolar (pp. 225-244). Buenos Aires: Del Estante Editorial.

Diker, G. (2008). ¿Cómo se establece qué es lo común? En G. Frigerio y G. Diker (comps.) Educar: posiciones acerca de lo común (pp. I47-I70). Buenos Aires: Del Estante Editorial.

Dussel, I. (2004). Inclusión y exclusión en la escuela moderna argentina: una perspectiva postestructuralista. Cadernos de Pesquisa, I22, 305-335.

Fraser, N. (2000). De la redistribución al reconocimiento? Dilemas de la justicia en la era postsocialista. New Left Review, $\mathrm{N}^{\circ}$ 0. Madrid: Akal.

Kessler, G. (2002). La experiencia escolar fragmentada. Estudiantes y docentes en la escuela media en Buenos Aires. Buenos Aires: IIPE-UNESCO.

Pineau, P. (2006). "Impactos de un asueto educacional: las políticas educativas de la dictadura (I976-I983)”, en P. Pineau, et al. El principio del fin. Políticas y memorias de la educación en la última dictadura militar (1976-1983). Buenos Aires: Colihue. 
Pineau, P. (2007). Algunas ideas sobre el triunfo pasado, la crisis actual y las posibilidades futuras de la forma escolar, en R. Baquero, G. Diker y G. Frigerio (comps.) Las Formas de lo Escolar (pp. 33-44). Buenos Aires: Del Estante Editorial.

Redondo, P. (2004). Escuelas y pobreza. Entre el desasosiego y la obstinación. Buenos Aires: Paidós.

Southwell, M. (2006). La tensión desigualdad y escuela. Breve recorrido de sus avatares en el Río de la Plata. En P. Martinis y P. Redondo (comps.) Igualdad y educación. Escrituras entre (dos) orillas (pp. 47-80). Buenos Aires: Del Estante Editorial.

Southwell, M. y Vassiliades, A. (20I4). El concepto de posición docente: notas conceptuales y metodológicas. Revista Educación, Lenguaje y Sociedad, II, I63-I87. General Pico: Instituto para el Estudio de la Educación, el Lenguaje y la Sociedad.

Terigi, F. (2008). Lo mismo no es lo común. En G. Frigerio y G. Diker (comps.) Educar: posiciones acerca de lo común (pp. 209-22I). Buenos Aires: Del Estante Editorial.

Tiramonti, G. (comp.) (2004). La trama de la desigualdad educativa. Mutaciones recientes en la escuela media. Buenos Aires: Manantial.

Vassiliades, A. (2014). El discurso pedagógico oficial en Argentina (200320I3): trabajo docente e igualdad. Cadernos de Pesquisa, I54, I0I2-I027. São Paulo: Fundação Carlos Chagas. 